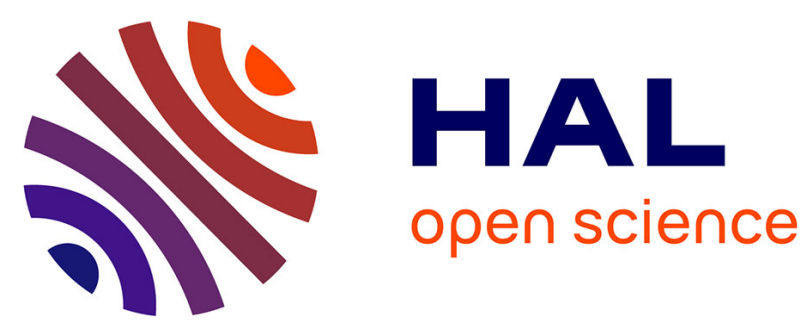

\title{
Biodegradable PLA/PBS multinanolayer membrane with enhanced barrier performances
}

Tiphaine Messin, Stéphane Marais, Nadège Follain, Alain Guinault, Valérie Gaucher, Nicolas Delpouve, Cyrille Sollogoub

\section{- To cite this version:}

Tiphaine Messin, Stéphane Marais, Nadège Follain, Alain Guinault, Valérie Gaucher, et al.. Biodegradable PLA/PBS multinanolayer membrane with enhanced barrier performances. Journal of Membrane Science, 2020, 598, pp.1-11. 10.1016/j.memsci.2019.117777 hal-02430440

\section{HAL Id: hal-02430440 \\ https://hal.science/hal-02430440}

Submitted on 6 Apr 2020

HAL is a multi-disciplinary open access archive for the deposit and dissemination of scientific research documents, whether they are published or not. The documents may come from teaching and research institutions in France or abroad, or from public or private research centers.
L'archive ouverte pluridisciplinaire HAL, est destinée au dépôt et à la diffusion de documents scientifiques de niveau recherche, publiés ou non, émanant des établissements d'enseignement et de recherche français ou étrangers, des laboratoires publics ou privés. 


\title{
Biodegradable PLA/PBS multinanolayer membrane with enhanced barrier performances
}

\author{
Tiphaine Messin $^{\mathrm{a}}$, Stephane Marais ${ }^{\mathrm{a}, *}$, Nadege Follain ${ }^{\mathrm{a}}$, Alain Guinault ${ }^{\mathrm{b}}$, Valerie Gaucher ${ }^{\mathrm{c}}$, \\ Nicolas Delpouve ${ }^{\mathrm{d}}$, Cyrille Sollogoub ${ }^{\mathrm{b}}$

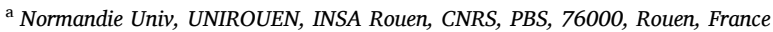 \\ ${ }^{\mathrm{b}}$ Laboratoire PIMM, ENSAM, CNRS, CNAM, Hesam Universite, 151, Bd de l'Hôpital, 75013, Paris, France \\ ${ }^{\mathrm{c}}$ Univ. Lille, CNRS, INRA, ENSCL, UMR 8207 - UMET - Unite Materiaux et Transformations, F-59000, Lille, France \\ ${ }^{\mathrm{d}}$ Normandie Univ, UNIROUEN Normandie, INSA Rouen, CNRS, Groupe de Physique des Materiaux, 76000, Rouen, France
}

\section{A R T I C L E I N F O}

\section{Keywords:}

Coextrusion

Multilayer film

Barrier properties

poly(lactic acid)

poly(butylene succinate)

\begin{abstract}
A B S T R A C T
Polyester multilayer membranes with more than 2000 alternating layers of poly(lactic acid) (PLA) and poly (butylene succinate) (PBS) were successfully prepared via a nanolayer coextrusion process equipped with a multiplying-element device. This process allows to make films consisting of very thin layers of polymers and in which a confinement effect of the semicrystalline polymer can be induced at point to significantly improve its physical properties. In this work, a homogeneous multinanolayer film of PLA/PBS was obtained without defaults or delamination, while the two polymers are immiscible. Continuous and homogeneous ultrathin layers of PBS ( $\sim 45 \mathrm{~nm}$ ) were obtained and the resulting confined structure of PBS led to an improvement of its barrier performances until $30 \%$ for oxygen, $40 \%$ for water and $70 \%$ for carbon dioxide. This improvement was explained by a decrease of the solubility coefficient and surprisingly not by the diffusion coefficient. This result was attributed to a slight orientation of the crystals in the extrusion direction and to the probable presence of an interphase between the layers of PLA and PBS.
\end{abstract}

\section{Introduction}

Thanks to their tunable properties, their lightness and their relatively low cost, polymer membranes are widely used in many applications such as packaging, transport, separation processes, building, energy or biomedical devices. However, due to the decrease in fossil resources, bio-based polymers have gained considerable attention, as well as in a sustainable development approach, the use of biodegradable, recycled and eco-friendly materials is of growing interest. Therefore, more and more bio-based and/or biodegradable polymers emerge as an alternative to petroleum-based polymers, for the packaging market, among which poly(lactid acid) (PLA) seems to be the most promising polymer for commercial use [1-3]. However, PLA presents some drawbacks and limitations, such as poor gas barrier properties, inherent brittleness or low heat resistance that strongly impede its industrial use [4,5]. Many various strategies have been proposed in the literature in order to enhance properties of PLA namely, for amelioration of its gas barrier properties: surface treatment (by plasma for instance Refs. [6-9]), incorporation of fillers to increase the tortuosity inside the polymer film
[10-12], or combination with other polymers [13]. One classical way to combine two polymers in packaging field is the coextrusion process. In the last few years, Baer's group from the Case Western Reserve University, has updated an innovative co-extrusion process which was developed in the 60 s $[14,15]$ and which permits to elaborate a multilayer film, composed of hundreds or thousands layers of two alternating polymers. The obtained nanostratified structure has been shown to exhibit significant enhanced properties (like gas barrier properties [16-19], mechanical properties [20-23] or even optical properties [24, 25]), due to confinement and/or interfacial effect. In particular, for some semi-crystalline polymers, the confinement generated by the nanostratified structure leads to specific orientation of the crystals, inducing an increase of the tortuosity for the diffusing molecules [26, 27].

In a previous work [28], we used this nanolayer coextrusion process to elaborate a multi-nanolayer film composed of two biodegradable polymers, PLA and poly(butylene succinate-co-butylene adipate) PBSA. Despite a slight crystal orientation, the significant improvement of barrier properties was attributed to an increase of the rigid amorphous

\footnotetext{
* Corresponding author.

E-mail address: stephane.marais@univ-rouen.fr (S. Marais).
} 


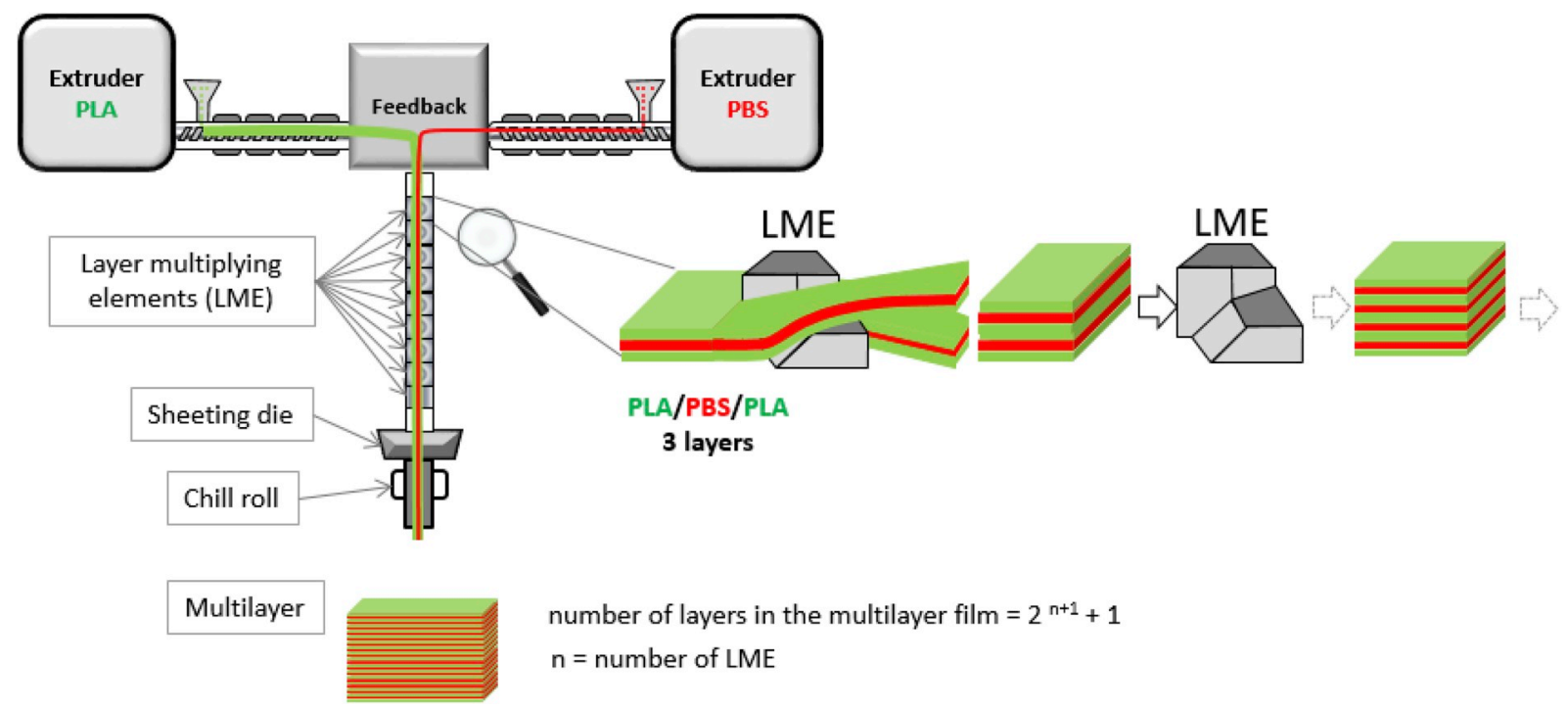

Fig. 1. Schematics of the multilayer coextrusion process.

fraction, presumably densified and thus less permeable. In this work, we report the elaboration of a biodegradable film composed of PLA and Poly (butylene succinate) PBS. This biodegradable aliphatic polyester is more crystalline than PBSA and has lower gas/water permeability compared to PLA. Previous studies on PLA/PBS blends [29-31] have pointed out the complementary mechanical properties of the two components, and have shown that, although immiscible, this blend does not require the use of a compatibilizer to offer good mechanical properties. Xie et al. have reported the interest of creating PBS nanofibrils [32] or nanosheets [33] in PLA matrix to obtain enhanced gas barrier and mechanical properties. In this study, we focus on the impact of a nanolayer structuration on gas/water barrier properties of PLA/PBS membrane.

\section{Experimental section}

\subsection{Materials}

Amorphous poly(lactic acid), referenced as 4060D, was supplied by Resinex (France) (L/D isomer ratio of 88:12, $\mathrm{T}_{\mathrm{g}} 55$ C, $\mathrm{M}_{\mathrm{w}} \quad 113,6 \mathrm{~kg} /$ $\mathrm{mol}$ ), and semi-crystalline poly(butylene succinate) (PBS), reference PBE003, was obtained from Natureplast (France) $\left(\mathrm{T}_{\mathrm{g}}-33 \mathrm{C}, \mathrm{M}_{\mathrm{w}}\right.$ $126 \mathrm{~kg} / \mathrm{mol}$ ). At a processing temperature of $180 \mathrm{C}$, the viscosities ratio between the two polymers was equal to 5.5 . The materials were dried at $60 \mathrm{C}$ during $12 \mathrm{~h}$ before the experiments in dried air SOMOS dryer.

\subsection{Films preparation}

The multilayer film PLA/PBS (80/20 wt\%) was elaborated with the multilayer coextrusion process, schematized in Fig. 1, by using 10 layermultiplying-elements (LMEs) to obtain in theory 2049 layers. Each polymer was melt in an extruder at $190 \mathrm{C}$ and then spread through the multilayer bloc at $180 \mathrm{C}$, the flat die at $170 \mathrm{C}$ and the chill roll at $40 \mathrm{C}$. The final thickness of the film was $225 \mu \mathrm{m}$, which in theory corresponds to layers of PBS of around $45 \mathrm{~nm}$. Monolayer films of PLA and PBS were also elaborated by classical extrusion at the same processing temperatures to serve as references for this work.

\subsection{Structural characterization}

The structure of the film was investigated by Atomic Force Microscopy (AFM) using a Veeco Nanoscope V in tapping mode. To facilitate the acquisition, a very smooth surface of the cross-section of the film was obtained using an ultramicrotome (LKB BROMMA 2088 Ultratome) equipped with a diamond knife.

Wide Angle X-ray Scattering (WAXS) experiments were performed at $50 \mathrm{kV}$ and $1 \mathrm{~mA}$ using a Genix microsource X-ray generator. The $\mathrm{Cu}-\mathrm{K}_{\alpha}$ radiation ( $\lambda \quad 1.54 \AA$ A ) was collimated with a FOX2D mirror and two pairs of Scatterless slits from Xenocs. Radial intensity profiles $I(2 \theta)$ were obtained by azimuthal integration of the 2D-patterns using FIT2D software. To characterize the crystalline phase, the average WAXS diffractogram is calculated from normalized radial intensity profiles $\mathrm{I}(2 \theta)$ recorded in the three principal directions of film. Crystal index was determined using the PeakFit software, and assuming Pearson profiles for all scattering peaks and amorphous halo. In the case of multilayer film PLA/PBS 80/20, the contribution of the PBS part was calculated by deducing the one of the PLA part from the raw diffractogramm.

DSC analyses were performed with a DSC Q2000 from TA Instruments on around 6-7 mg of sample, at a heating/cooling rate of 10 $\mathrm{C} / \mathrm{min}$ from 60 to $200 \mathrm{C}$ in aluminum pan, under a nitrogen flow of $50 \mathrm{~mL} / \mathrm{min}$. Calibration in temperature and energy was carried out using standard values of indium. The first heating step was used to determine the degree of crystallinity because the permeation measurements were realized with this crystallinity degree.

The degree of crystallinity, $X_{c}$, was determined by the following equation:

$X_{c} \quad \% \quad \frac{\Delta H_{m} \quad \Delta H_{c}}{\Delta H_{m}^{0}} 100$

where $\Delta H_{m}$ is the melting enthalpy, $\Delta H_{c}$ is the enthalpy of crystallization and $\Delta H_{m}^{0}$ is the melting enthalpy of a $100 \%$ theoretical crystalline polymer. For the PBS, $\Delta H_{m}^{0}$ is equal to $110.3 \mathrm{~J} / \mathrm{g}$ [34].

Modulated differential scanning calorimetry (MT-DSC) investigations were performed in DSC Q2000. The specific heat capacity measurement was calibrated using sapphire. Experimental conditions were as follows: heating rate of $2 \mathrm{~K} / \mathrm{min}$, amplitude $0.32 \mathrm{~K}$, and modulation period of $60 \mathrm{~s}$.

Fast scanning calorimetry (FSC) measurements were realized by using a Mettler Toledo Flash DSC 1. Samples positioned on a chip sensor were flushed by gaseous nitrogen at $20 \mathrm{~mL} / \mathrm{min}$. Before any experiment, the chip was conditioned. Sample mass was determined by doing the comparison between the heat capacity step $\Delta \mathrm{Cp}$ obtained from the glass transition in MT-DSC and FSC on a sample at the amorphous state. More details regarding the recommended protocol for FSC analysis of multilayer samples were given in the work of Monnier et al. [35].

Dynamic mechanical thermal analyses (DMTA) were carried out 


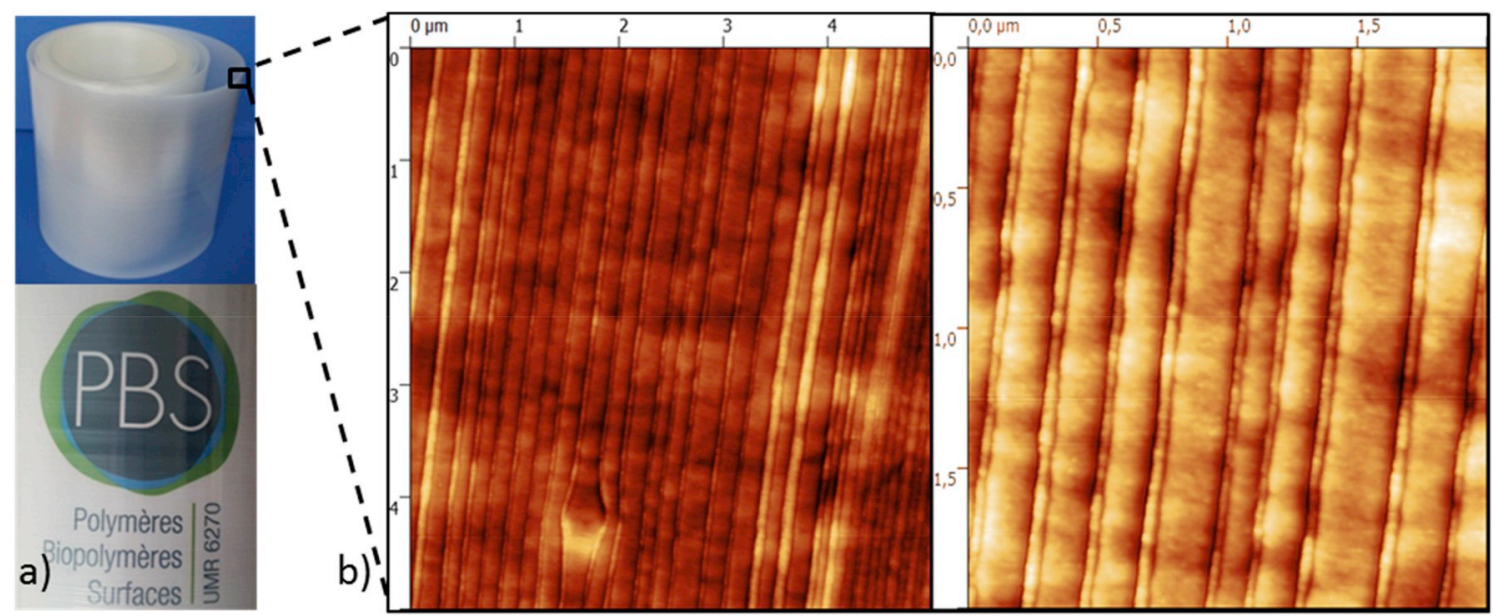

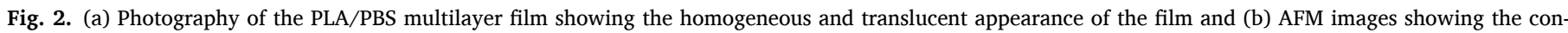
tinuity of the thin layers of PBS into the PLA/PBS (80/20 wt\%) multilayer film.

using a DMA Q800 from TA Instruments. The temperature was increased from 80 to $100 \mathrm{C}$ with a heating speed of $2 \mathrm{C} / \mathrm{min}$. The analyze was performed using dynamic tensile mode with a frequency of $1 \mathrm{~Hz}$ and an oscillation strain of $0.2 \%$ on small bar samples ( $5 \mathrm{~mm}$ width).

\subsection{Transport properties}

Gas permeation measurements were performed at $25 \mathrm{C}$ according to the barometric method with a homemade apparatus [36]. After a purge of $15 \mathrm{~h}$ of the permeation cell containing the sample by vacuum, a pressure sensor monitored the increase of pressure in the downstream compartment when the gas $\left(\mathrm{O}_{2}\right.$ or $\mathrm{CO}_{2}$ at a pressure of 4 bars) was sent to the upstream compartment and then passed through the sample thickness $(L)$. The permeability coefficient $P$, was determined from the steady state of permeation process:

$P \quad \frac{J s t L}{\Delta p}$

where Jst is the stationary flux, $L$ is the film thickness and $\Delta p$ is the difference of pressure between the upstream and the downstream parts of the permeation cell.

The stationary flux $J s t$, was determined at long time from the slope $\alpha$ of the kinetic curve according to:

Jst $\frac{\alpha V}{A R T}$

where $V$ is the volume of the downstream compartment, $A$ is the film surface in contact with gas, $R$ is the ideal gas constant and $T$ is the experimental temperature.

By taking into account that there was no plasticization effect caused by the gas molecules during the measurement, the diffusion coefficient $D$ can be assumed constant and determined as follows:

$D \frac{L^{2}}{6^{*} t_{l}}$

where $t_{l}$ is the well-known time called "time-lag" which was determined from the intercept of the asymptotic straight line of the stationary flux with the time axis; and $L$ is the thickness of the sample.

On the basis that the permeability coefficient is the product of the diffusivity and the solubility coefficients, the solubility coefficient $S$ can be deduced from:

$S \frac{P}{D}$
Water permeation measurements were achieved at $25 \mathrm{C}$ with a labbuilt device [36]. First, in order to purge the permeation cell containing the film, the permeation cell was swept by dry nitrogen until reaching a low constant dew point $(<70 \mathrm{C}$ and that corresponds to very low water content $<2.5 \mathrm{ppmV}$ ) which was monitored by a chilled mirror hygrometer (Elcowa $\AA$, France, General Eastern Instruments). Then the upstream compartment was filled with liquid water (milli Q) and the water permeation flux was measured at downstream by following the increase of the dew point temperature as function of time. At the stationary state, the permeability coefficient $P$, expressed in Barrer (1 Barrer $10^{-10} \mathrm{~cm}^{3}$ (STP) $\mathrm{cm} \mathrm{cm}^{-2} \mathrm{~s}^{-1} \mathrm{cmHg}^{-1}$ ) was calculated according to:

$P \quad \frac{J s t^{*} L}{\Delta a}$

with $J s t$ is the stationary flux, $L$ is the thickness of the film and $\Delta a$ is the difference of water activity between the two compartments of the permeation cell (in our case $\Delta a \quad 1$ ).

From the well-known series model usually applied for multilayer structure, it is possible to predict the permeability coefficient for our PLA/PBS multilayer films [19,37-39], using the following equation:

$\frac{1}{P_{\text {Film }}} \quad \frac{\phi_{\mathrm{PLA}}}{P_{\mathrm{PLA}}} \quad \frac{\phi_{\mathrm{PBS}}}{P_{\mathrm{PBS}}}$

where $\phi i$ is the volume fraction and $P i$ is the permeability coefficient, the index i corresponding to polymers (PLA or PBS). The volume fraction was determined thanks to the weight fraction and the density of each polymer ( $\mathrm{d}_{\mathrm{PLA}} \quad 1.24$; $\left.\mathrm{d}_{\mathrm{PBS}} \quad 1.26\right)$.

\section{Results and discussion}

\subsection{Structure and morphology}

First of all, a good film quality, relevant for the packaging market, was achieved, as can be observed in Fig. 2 a. Indeed, the obtained multilayer film was homogeneous, translucent without any delamination phenomenon. AFM observations were undertaken on the cross section of the film to visualize the microstructure and investigate the multilayer structure. As clearly shown in Fig. 2 b, a homogeneous multilayer structure was obtained with continuous and reasonably regular PBS layers, with a thickness between 40 and $50 \mathrm{~nm}$ (measured following the method proposed by Bironeau et al. [40]) as expected, suggesting that the $80 / 20$ wt ratio between PLA and PBSA was respected. 


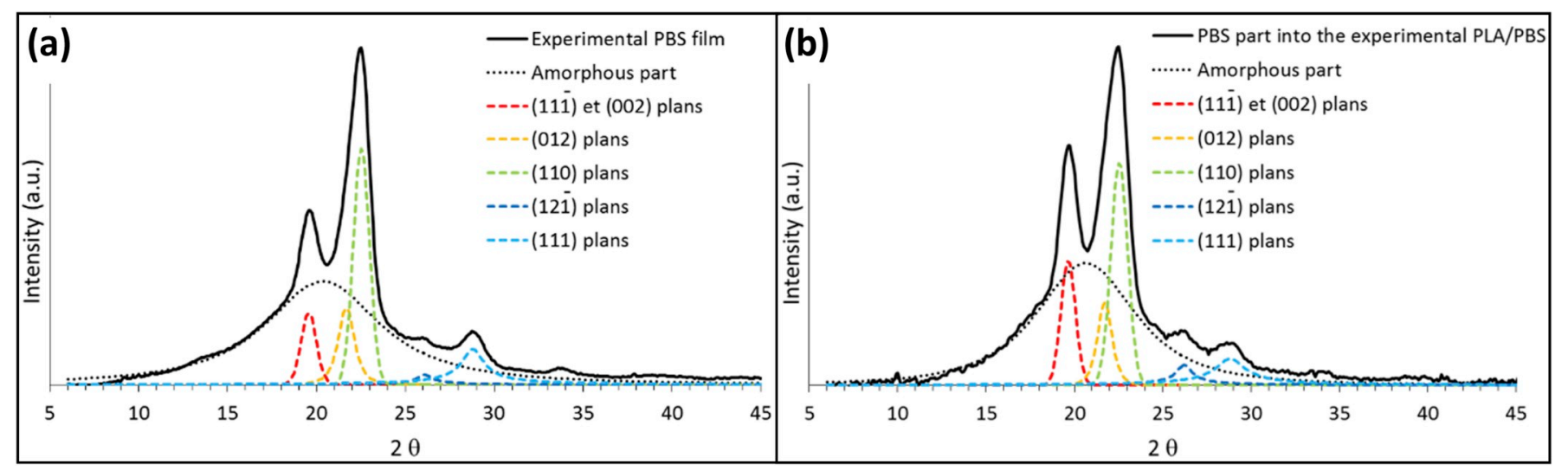

Fig. 3. Deconvolution of WAXS diffractogramms highlighting the amorphous halo and the diffraction plans for (a) the PBS monolayer film and (b) the PBS part into the PLA/PBS multilayer film.
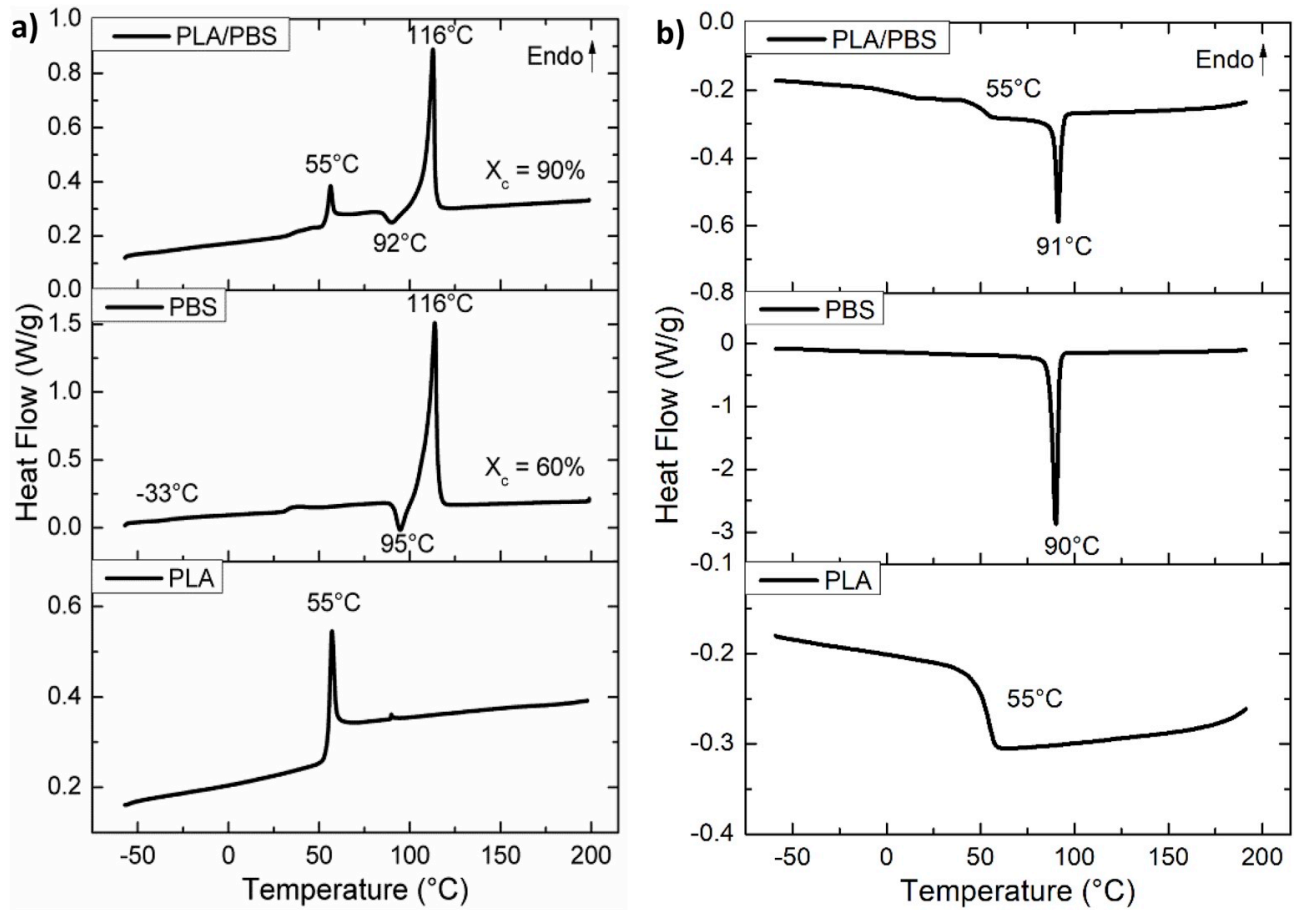

Fig. 4. (a) First heat and (b) cooling DSC curves of the PLA and PBS monolayer films and of the PLA/PBS multilayer film.

\subsection{Structural characterization}

\subsubsection{Crystallinity}

XRD analyses were carried out in order to see the impact of the multilayer structure on the crystalline phase of the PBS and on the orientation of the crystals. The contribution of PBS within the PLA/PBS multilayer film was extracted (Fig. 3 b) to be compared with the different crystalline planes of those obtained for a monolayer film of PBS (Fig. 3 a). The assignment of the peaks was made from the work of Nikolic and Djonlagic [41]. Whether the PBS is in monolayer or multilayer form, it has the same diffraction planes, which means that its crystalline phase is similar in both cases. Note that the intensity of the diffraction related to the $(11 \overline{1}$ and (002) planes for the PLA/PBS multilayer film is slightly more pronounced than for the PBS monolayer. This observation suggests that the confinement of the PBS in nanolayers tends to favor the formation of the (11 $\overline{1}$ and (002) planes.

XRD curves were also used to determine the crystal index of the PBS in the neat and the multilayer film and it was found equal to around 37 and $40 \%$ respectively. These values are slightly lower in comparison with the work of Phua et al. [42], in which $\mathrm{X}_{\mathrm{c}} \quad 49 \%$ was determined from WAXS.

The degree of crystallinity was also investigated from DSC. The curves are plotted in Fig. 4 and the characteristic temperatures (transition temperature $\mathrm{T}_{\mathrm{g}}$, cold crystallization temperature $\mathrm{T}_{\mathrm{cc}}$, and melting temperature $\mathrm{T}_{\mathrm{m}}$ ) are noted on the graph. It was chosen to determine these temperatures on the first heat curve (Fig. 4a), because it corresponds to the same structure state of the material as when it was analyzed by permeation measurements. The $\mathrm{T}_{g}$ value obtained for PLA and the melting and cold-crystallization behavior of PBS are in good agreement with the literature [42,43]. The glass transition of PBS is hardly visible in monolayer film and almost indiscernible in multilayer film because PBS is highly crystalline. Indeed, as presented in Fig. 4b, PBS crystallizes quickly during cooling from the melt. According to calculation from DSC measurements, $\mathrm{X}_{\mathrm{c}} \quad 60 \%$ for pure PBS. This value is consistent with the results reported in the literature from DSC investigations $[11,34,42]$ but differs from the results obtained from WAXS.

Surprisingly, for the PLA/PBS film an important increase of the PBS 


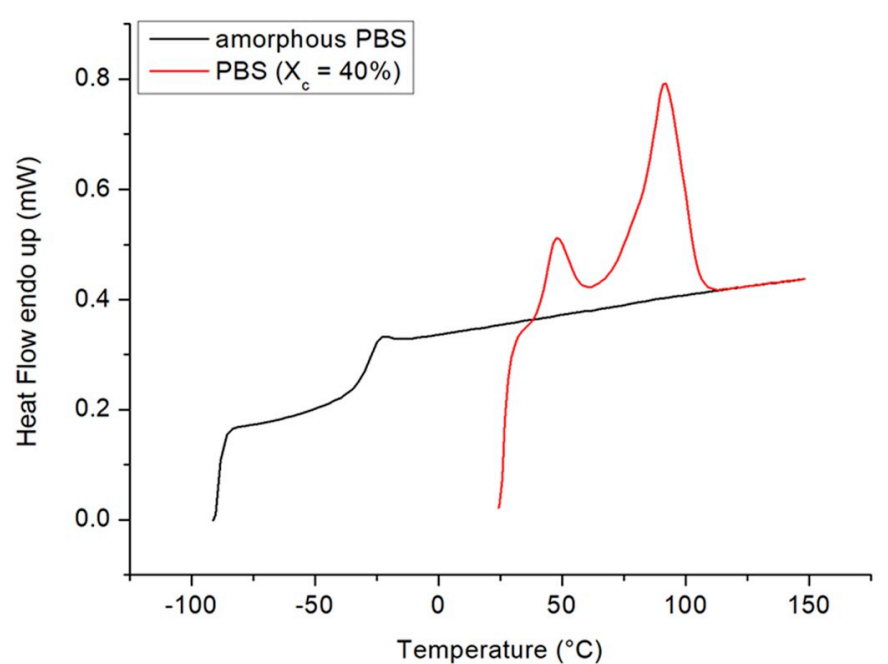

Fig. 5. FSC curves of amorphous and semi-crystalline PBS monolayer film recorded at $1000 \mathrm{C} / \mathrm{s}$.

Table 1

Melting enthalpy and crystallinity of PBS in monolayer and multilayer films obtained from FSC

\begin{tabular}{|c|c|c|c|c|}
\hline \multirow[b]{2}{*}{ Time } & \multicolumn{2}{|c|}{ PBS monolayer film } & \multicolumn{2}{|c|}{ PBS into PLA/PBS multilayer film } \\
\hline & $\Delta \boldsymbol{H}_{m}(\mathrm{~J} / \mathrm{g})$ & $X_{c}(\%)$ & $\Delta \boldsymbol{H}_{m}(\mathrm{~J} / \mathrm{g})$ & $X_{c}(\%)$ \\
\hline $15 \min$ & 46.9 & 43 & Non measurable & Non measurable \\
\hline $30 \mathrm{~min}$ & 75.5 & 62 & 5.4 & 5 \\
\hline $45 \mathrm{~min}$ & 77.1 & 70 & 15.8 & 14 \\
\hline $180 \mathrm{~min}$ & 79.1 & 72 & / & / \\
\hline $24 \mathrm{~h}$ & / & / & 84.1 & 76 \\
\hline
\end{tabular}

crystallinity degree from $60 \%$ to $90 \%$ was calculated from DSC, leading to a huge difference in comparison to results obtained from XRD. Discrepancy between results obtained from XRD and DSC is not common; however it has been previously reported for quenched polyethylene terephthalate (PET) [44]. In the case of PET, this discrepancy resulted from crystalline reorganization that could be tracked by modulated calorimetric measurements, but not by classical DSC. In most of the studied multilayer systems the degree of crystallinity remains constant even with the confinement effect induced by the forced assembly. Therefore, it is assumed that crystalline reorganization occurs in
PBS during DSC analysis, and in higher proportions for multilayer films.

\subsubsection{Evidence of reorganization from FSC}

In FSC, the high heating/cooling rates $(1000 \mathrm{C} / \mathrm{s})$ that are used, allow obtaining thermal signatures characteristics of the sample initial microstructure by preventing reorganization [45], and eventually amorphizing the polymer. The first analyze (Fig. 5) was made on the PBS monolayer film and the film was heated from ambient temperature to 150 C. Two endotherms were observed: the first was immediately followed by an exotherm, evidencing a process of melt-recrystallization of imperfect crystals. The second corresponds to the melting of a more organized crystalline phase. A second scan performed at $1000 \mathrm{C} / \mathrm{s}$ was superimposed to show the behavior of pure amorphous PBS. Due to the perfect alignment of the liquid lines between amorphous and semi-crystalline PBS, the calculation of the degree of crystallinity was possible. A value of $X_{c} \quad 40 \%$ was obtained, which is consistent with $\mathrm{XRD}$ results. Therefore, it is evidenced that the $\mathrm{X}_{\mathrm{c}}$ values obtained from classical DSC are higher because of crystalline reorganization.

\subsubsection{Degree of crystallinity}

After this first point, it became interesting to compare the degree of crystallinity of PBS under monolayer and multilayer form by FSC. For both films, the melting enthalpy was measured at different times of crystallization $t_{c}$, and the results are gathered in Table 1 and on Fig. 6 . For $t_{c} 15$ min, PBS is still amorphous in the multilayer film, whereas $\mathrm{X}_{\mathrm{c}} \quad 43 \%$ in monolayer film. For $\mathrm{t}_{\mathrm{c}} \quad 45 \mathrm{~min}, \mathrm{X}_{\mathrm{c}} \quad 14 \%$ in multilayer film while PBS reaches its maximum extent of crystallinity in monolayer film. This shows that the crystallization kinetics is slowed down in multilayer film. When crystallization is complete, both systems exhibit close values: $\mathrm{X}_{\mathrm{c}} \quad 72 \%$ in monolayer film ( $\mathrm{t}_{\mathrm{c}} \quad 180 \mathrm{~min}$ ), and $\mathrm{X}_{\mathrm{c}} \quad 76 \%$ in multilayer film ( $\left.\mathrm{t}_{\mathrm{c}} \quad 24 \mathrm{~h}\right)$.

\subsubsection{Orientation}

While XRD measurements performed in the three directions reveal an isotropic structure for the PLA and PBS monolayer films, an orientation effect is evidenced in the case of the PLA/PBS multilayer film as illustrated in Fig. 7. In particular, the slightly more pronounced diffraction of the (11) and (002) planes in meridional positions for both transverse and extrusion directions patterns suggests a weak orientation of the chain axis of PBS into the film plane.

A similar slight chain orientation was observed for poly(butylene succinate-co-adipate) (PBSA) in a PLA/PBSA multilayer structure [28]. Like for PBSA, we assume that PBS layer thickness of $50 \mathrm{~nm}$ is probably not sufficiently thin to force a strong crystal alignment. As a comparison,
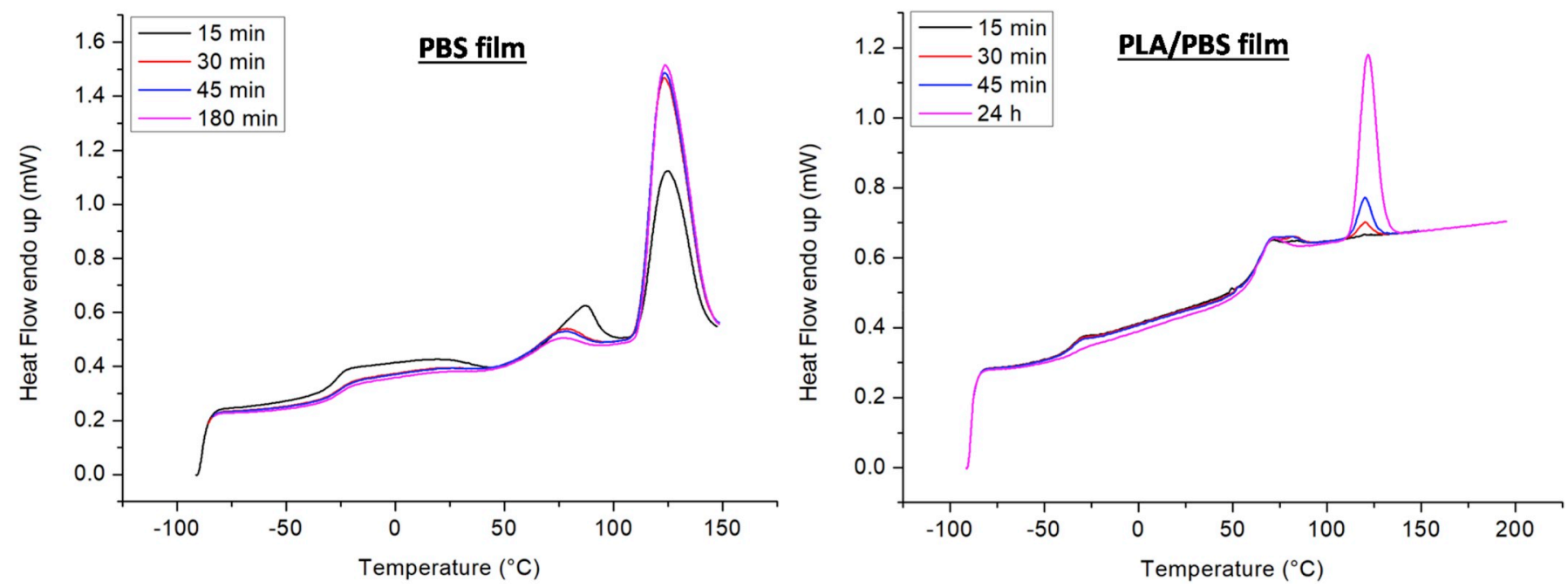

Fig. 6. FSC curves for PBS monolayer film and the PLA/PBS multilayer film at different times of crystallization. 


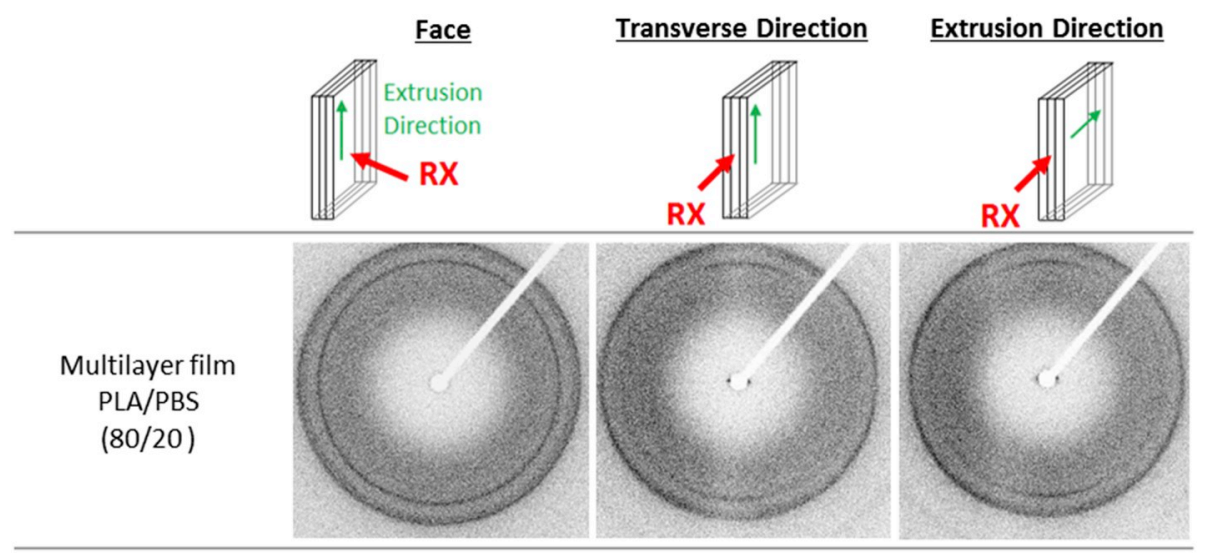

Fig. 7. WAXS patterns for the multilayer film of PLA/PBS $(80 / 20)$ performed in the three directions.

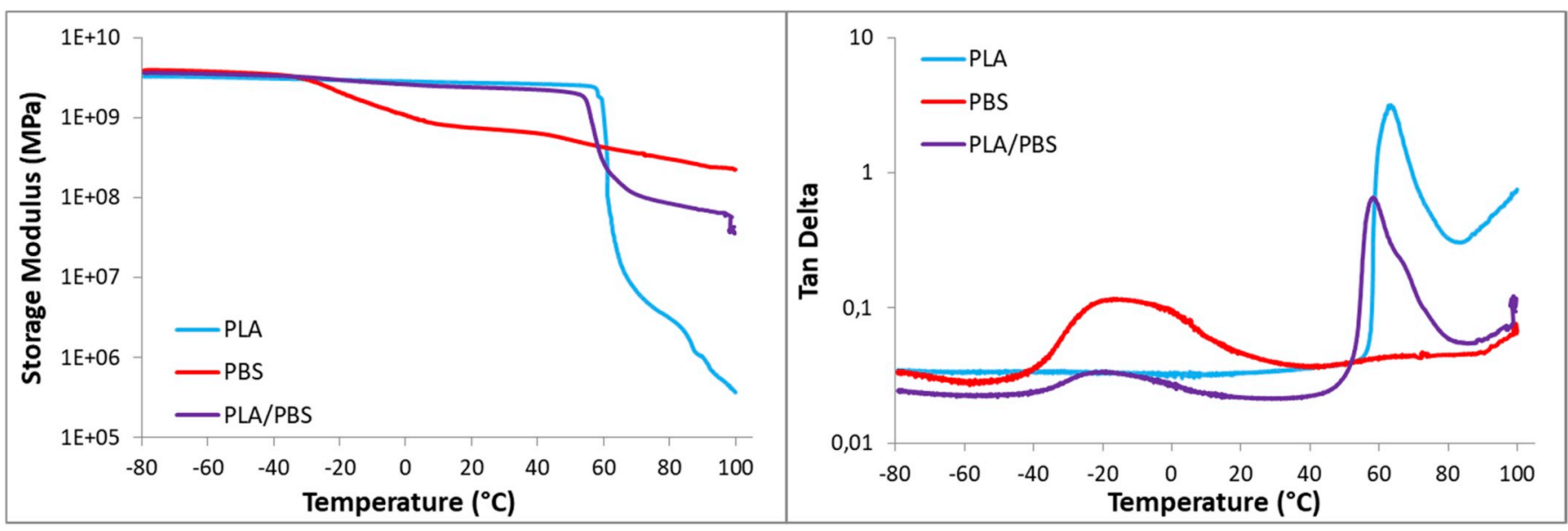

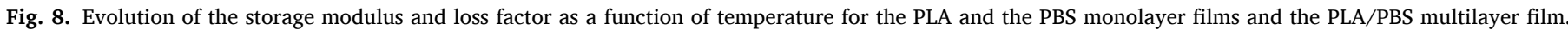

Baer et al. [16] have clearly shown in the case of EAA/PEO multilayer films, that an orientation started to appear for PEO layer thicknesses around $100 \mathrm{~nm}$, and became very pronounced when the size of the layers reached $20 \mathrm{~nm}$. In our case, a slight orientation begins to appear at 50 $\mathrm{nm}$ and could probably be more marked for thinner layers. However, the reduction of the layer thickness could lead to a layer breakup phenomenon [46] and induce a deterioration of the desired barrier effect [47].

Besides, by analyzing the cooling DSC curves of the studied polymers (Fig. 4b), a high difference between the crystallization temperature of PBS (90 C) and the glass transition temperature of PLA (55 C) can be noted. This means that during the cooling, after the extrusion, PBS can begin to crystallize without any strong constrain from PLA, this one being in rubbery state for temperature superior to $55 \mathrm{C}$. The slight orientation of the PBS crystals can also be explained by this "soft confinement" provided by PLA, while in rubbery state.

\subsubsection{Interphase}

The storage modulus and the loss factor (tan delta) obtained from DMTA for the PLA and the PBS monolayer films and for the PLA/PBS multilayer film are gathered in Fig. 8. The glass transition of PBS in multilayer film is not discernible in the storage modulus signal (Fig. 8a), but is detected in the Tan Delta signal (Fig. 8b), occurring in the same temperature domain as in monolayer film. As shown in Fig. 8a, the glass transition of PBS in multilayer film does not cause a drop of storage modulus which remains close to $3 \mathrm{GPa}$. This is probably linked to the low content of material that relaxes in this temperature range. Indeed $80 \%$ of the material is glassy rigid PLA; moreover PBS contains $40 \%$ of crystals.
When the glass transition of PLA is reached, the modulus in the multilayer film decreases down to $0.1 \mathrm{GPa}$, but the crystalline phase of PBS still provides some rigidity in comparison with bulk PLA. As a result, the multilayer film exhibits decent mechanical properties in the investigated temperature range.

Furthermore, it can be observed that the glass transition of PLA, obtained from the Tan Delta curve, decreases from $64 \mathrm{C}$ in monolayer film to $58 \mathrm{C}$ in multilayer form. This phenomenon could be attributed to the presence of an interphase between the layers of PLA and PBS in the multilayer films. The creation of such an interphase is possible due to the compatibility between both polyesters and via the transesterification reaction between a polyester group and an alcohol of end-chain. Also, one can suppose that in this interphase covalent bonds can be created leading to copolymer chains of PLA-co-PBS. This good compatibility was also observed for PLA/PBSA multilayer films [28], for which the absence of delamination during tensile tests and after breaking revealed the high quality of adhesion between PLA and PBSA layers.

\subsection{Barrier properties}

Permeation measurements of water and gases $\left(\mathrm{N}_{2}, \mathrm{O}_{2}\right.$ and $\left.\mathrm{CO}_{2}\right)$ were performed to evaluate the transport properties of the prepared multilayer film and the gain in barrier performances due to the nanostratification. The values of the permeability coefficients $P$ calculated for the PLA and PBS monolayer films are given in Table 2 and are in accordance with those already obtained in previous works for PLA [48, 49] and PBS [11]. For this latter, very few data on gases and water permeation are available in literature. 
Table 2

Gas and liquid water permeability coefficients for PLA and PBS monolayer films and PLA/PBS multilayer film.

\begin{tabular}{lllll}
\hline & \multicolumn{4}{l}{ Permeability coefficients $\mathrm{P}\left(\mathrm{Barrer}^{\mathrm{a}}\right)$} \\
\cline { 2 - 5 } & $\mathrm{N}_{2}$ & $\mathrm{O}_{2}$ & $\mathrm{CO}_{2}$ & $\mathrm{H}_{2} \mathrm{O}$ \\
\hline PLA monolayer & 0.069 & 0.320 & 0.80 & 2510 \\
& 0.003 & 0.001 & 0.03 & 124 \\
PBS monolayer & 0.109 & 0.196 & 1.725 & 2215 \\
& 0.007 & 0.003 & 0.006 & 142 \\
PLA/PBS multilayer & 0.085 & 0.253 & 0.722 & 2150 \\
& 0.001 & 0.006 & 0.007 & 63 \\
Calculated Permeability series & 0.074 & 0.285 & 0.896 & 2446 \\
$\quad$ model, Eq. (7) & & & & \\
Calculated $P_{P B S}$ in PLA/PBS & - & 0.137 & 0.513 & 1357 \\
Barrier Improvement Factor (\%) & - & 30 & 70 & 39 \\
$\quad$ of the confined PBS layers & & & &
\end{tabular}

a 1 Barrer $10^{-10} \mathrm{~cm}^{3}(\mathrm{STP}) \cdot \mathrm{cm} \cdot \mathrm{cm}^{-2} \cdot \mathrm{s}^{-1} \cdot \mathrm{cmHg}^{-1}$.

\subsubsection{Gas barrier properties}

The gas permeability, diffusion and solubility coefficients for the PLA and PBS monolayer films and the PLA/PBS multilayer film are presented in Fig. 9. As expected, the values of the gas permeability coefficients are ranked as follows: $\mathrm{P}_{\mathrm{CO} 2}>\mathrm{P}_{\mathrm{O} 2}>\mathrm{P}_{\mathrm{N} 2}$. In most cases, the values of the permeability coefficients of the multilayer film were found inferior to those of the neat PLA or/and the neat PBS films. To highlight the impact of the multilayer structure on barrier properties and to understand why the multilayer film has better barrier properties compared to the two neat polymers, permeabilities should be analyzed on the basis of the diffusion and solubility coefficients, considering that these both parameters govern the gas transfer.

Firstly, concerning the gas diffusivity in the PLA film, the following trend has been obtained: $\mathrm{D}_{\mathrm{CO} 2}<\mathrm{D}_{\mathrm{N} 2}<\mathrm{D}_{\mathrm{O} 2}$. This trend agrees well with the steric hindrance according to the van der Waals diameters of the different permeant molecules which are 42.67, 39.13 and $31.83 \mathrm{~cm}^{3}$. $\mathrm{mol}^{-1}$ for carbon dioxide, nitrogen and dioxygen, respectively. On the other hand, in the case of PBS, another trend was obtained for the gas diffusivity: $\mathrm{D}_{\mathrm{N} 2}<\mathrm{D}_{\mathrm{CO} 2}<\mathrm{D}_{\mathrm{O} 2}$. This order would be more consistent by considering the molecular size deduced from the kinetic diameter of $\mathrm{N}_{2}$ (3.64 $\AA$ ) and $\mathrm{CO}_{2}(3.30 \AA)$. To date, the choice of the molecular size is not well defined to explain the molecular diffusivity in polymers. If the diffusivity follows the van der Waals volume in most cases for glassy and rubbery polymers [50], in some cases it follows the kinetic diameter like for PBSA [28] or PHBV [51]. Anyway, it is interesting to notice that same tendencies in gas diffusivity have been obtained for PBS in previous work [11] or for PBSA (poly(butylene succinate-co-adipate)), a copolymer of PBS [28].

Concerning the multilayer film, the fact that the values of the gas diffusivity follow the same trend as for PLA is not surprising, since PLA is the major component of the multilayer film $(80 \%)$. Thus in the multilayer film of PLA/PBS, the diffusion of gases should be rather dependent on the van der Waals diameters, so that the molecular size of $\mathrm{CO}_{2}$ would be higher than that of $\mathrm{O}_{2}$ and $\mathrm{N}_{2}$. The values of the diffusion coefficients are not lowered in the multilayer film in comparison with monolayer films, except in the case of the carbon dioxide for which the diffusion coefficient is reduced compared to PBS (it is similar for dioxygen and even superior for nitrogen). This result would indicate that the multilayer structure has not induced additional tortuosity, which is not really surprising since the degree of crystallinity of PBS has not changed, the PBS crystals in the nanolayers have not been strongly oriented, (as evidenced by XRD measurements).

Comparing the solubility coefficients of the three films, we observe that they are lowered in the case of the multilayer film compared to monolayer films of PLA and PBS, which is certainly at the origin of the improvement of the barrier properties (similar evolution of the solubility and permeability coefficients).

This trend has already been observed for a similar multilayer system
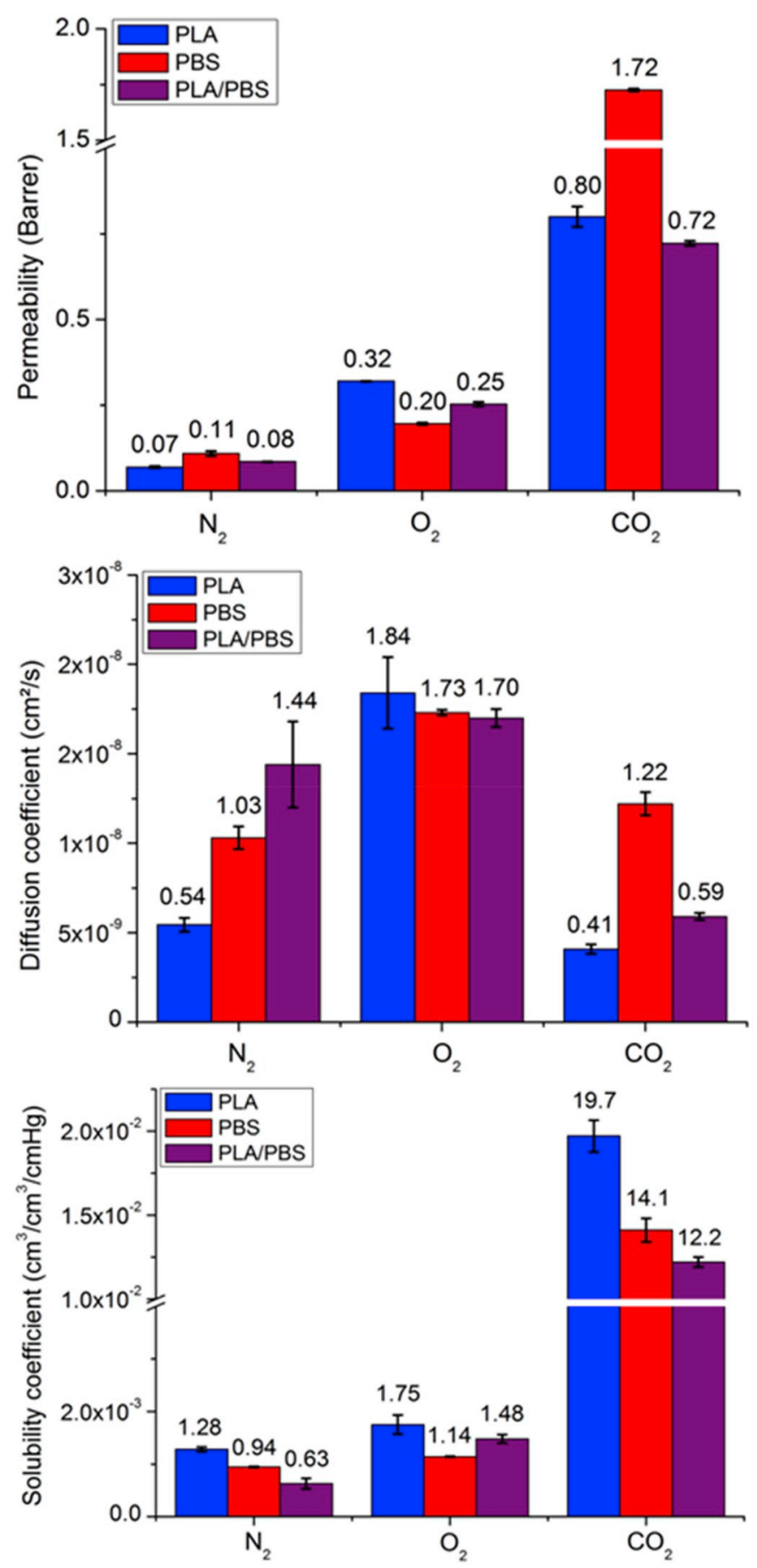

Fig. 9. Comparison of the gas permeability, diffusion and solubility coefficients for the monolayer films of PLA and PBS and the PLA/PBS multilayer film.

made with PLA and PBSA [28], and for which the highest barrier improvement was observed for the carbon dioxide. Similarly, the gas barrier effect obtained in the multinanolayer PLA/PBS would rather be due to a reduction of the solubility as the gas diffusivity has not decreased (has even increased for nitrogen, as revealed by the diffusion coefficient values) (Fig. 9). It seems therefore that the reduction of the gas concentration in the PLA/PBS multilayer would be responsible for the gas barrier effect.

One explanation of this result could be that the confinement of the PBS layers by the PLA layers may lead to a denser structure with reduced free volumes, limiting thus the space for gas molecules to be absorbed. In addition, it is possible that some constrained amorphous chains in 

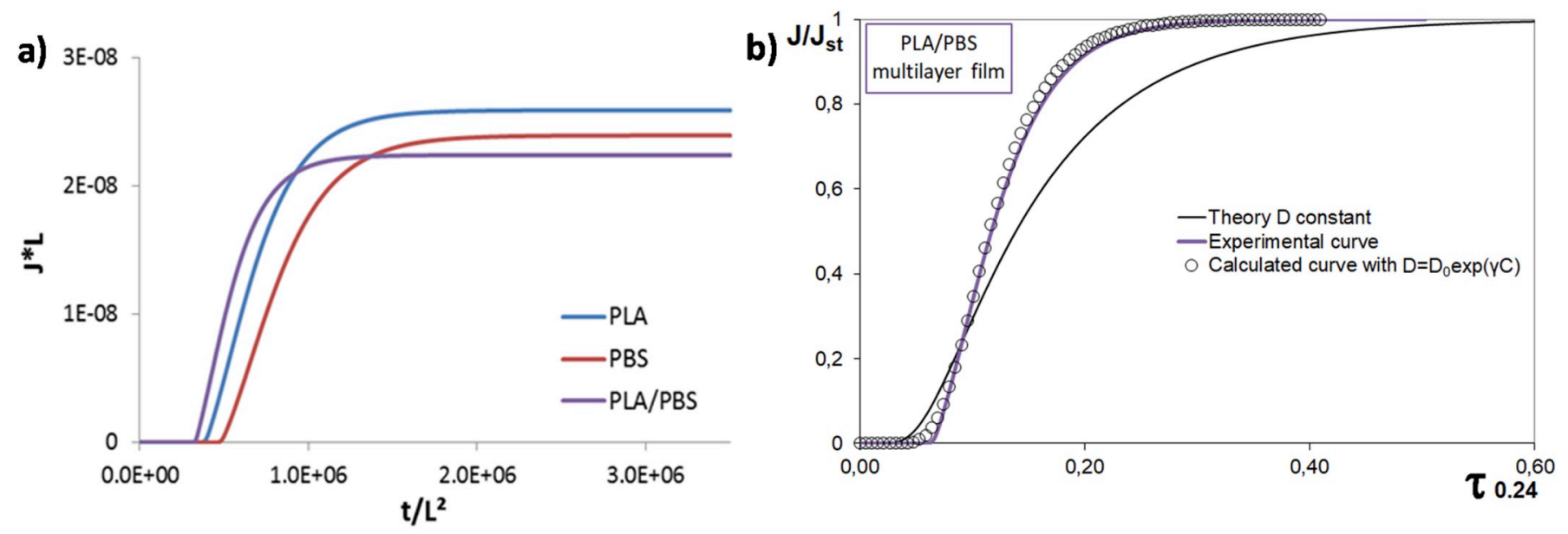

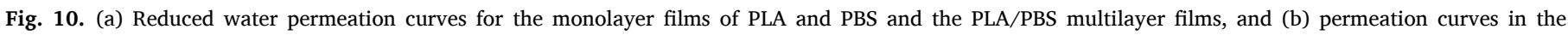
dimensionless scale of flux and time for the PLA/PBS multilayer film.

Table 3

Water permeation parameters for the monolayer films of PLA and PBS and the multilayer film of PLA/PBS.

\begin{tabular}{|c|c|c|c|c|c|c|c|c|c|c|c|c|}
\hline \multirow[b]{2}{*}{ PLA film } & \multicolumn{2}{|c|}{$\mathrm{P}$ (Barrer) } & \multicolumn{2}{|c|}{$\mathrm{D}_{0}\left(10^{-8} \mathrm{~cm}^{2} \cdot \mathrm{s}^{-1}\right)$} & \multicolumn{2}{|c|}{$\mathrm{D}_{\mathrm{M}}\left(10^{-8} \mathrm{~cm}^{2} \cdot \mathrm{s}^{-1}\right)$} & \multicolumn{2}{|c|}{$\gamma \mathrm{C}_{\mathrm{M}}$} & \multicolumn{2}{|c|}{$\gamma\left(\mathrm{cm}^{3} \cdot \mathrm{mmol}^{-1}\right)$} & \multicolumn{2}{|c|}{$\mathrm{C}_{\mathrm{M}}\left(\mathrm{mmol} . \mathrm{cm}^{-3}\right)$} \\
\hline & 2510 & 124 & 0.87 & 0.07 & 11.6 & 0.7 & 2.6 & 0.2 & 4.0 & 0.1 & 0.67 & 0.03 \\
\hline PBS film & 2215 & 142 & 0.64 & 0.07 & 10.1 & 0.1 & 2.8 & 0.2 & 4.0 & 0.5 & 0.69 & 0.04 \\
\hline PLA/PBS multilayer film & 2150 & 63 & 1.03 & 0.05 & 11.5 & 0.3 & 2.5 & 0.8 & 4.6 & 0.8 & 0.54 & 0.01 \\
\hline
\end{tabular}

confined spaces can hinder the access of gas in some free reduced volumes. However, we believe that this local increase in stiffness leading to more rigid spaces is not enough to affect diffusivity. If this had been the case, we would have had a noticeable reduction in the diffusion coefficient values, which is not the case.

Moreover, the existence of a PLA/PBS interphase could have an impact on the transport of gas molecules. Even if this interphase is very thin, the high number of interfaces of this nanostratified structure may amplify its effect. From the one hand, it can be supposed that the interphase, because of the presence of some entangled chains of PLA and PBS but also some longer chains due to the formation of covalent bonds between them, can hinder the passage of the gas molecules. From the other hand, the proportion of PBS crystallinity chains in this thin interphase is lowered, reducing the obstacles in the diffusion pathways through this interphase.

\subsubsection{Water barrier properties}

To complete the observations made with the gas permeation results, water permeation kinetic measurements were carried out on the three studied films (Fig. 10 a) and the obtained data are gathered in Table 3. As for the various gases, the PLA/PBS multilayer film has a lower permeability to water than monolayer films of PLA and PBS.

From the kinetic point of view, the analysis of the water permeation curves has shown that the diffusion is not constant but depends on the water concentration. This water concentration-dependence of the diffusion coefficient is typical of a water plasticization effect. Therefore, due to an increase of the chain segment mobility by plasticization, the water diffusivity increases during the extent of water permeation and an exponential law (Eq. (8)) is usually convenient to describe this mechanism of diffusivity which originates from the free volume theory [52, 53]:

\section{D $\quad \mathrm{D}_{0} \exp (\gamma \mathrm{C})$}

The experimental flux curves have been fitted using this concentration-dependent diffusion coefficient, from which it was possible to determine the different coefficients of this law such as $\mathrm{D}_{0}$ and $\mathrm{D}_{\mathrm{M}}$ : the diffusion coefficients taken at the boundary conditions from $\mathrm{C}$

0 and $C C_{M}$ (stationary state), $\gamma C_{M}$ the plasticization coefficient, and $\gamma$ the plasticization factor. Fig. $10 \mathbf{b}$ displays permeation curves in the dimensionless scale of flux and time $\left(\mathrm{J} / \mathrm{J}_{\mathrm{st}}\right.$ as a function of $\tau$ D.t $\left./ \mathrm{L}^{2}\right)$. A strong deviation can be observed between the experimental curves for the multilayer PLA/PBS film and the theoretical curve when D is taken constant (calculated from Fick's laws), while a perfect fit is obtained using Eq. (8) for the diffusivity, which validates the water plasticization occurring in the multilayer film. This plasticization phenomenon has also been observed for the PLA and the PBS monolayer films, as well as in other studies [7,54-57].

It is clear that the water permeation depends both on this increase of $\mathrm{D}$ and on the solubility. The solubility could be also influenced by this plasticization effect, as it may locally increase the free volume, but in a lesser extent compared to the increase of chain segment mobility that favours water diffusivity. The fact that the water solubility coefficient is decreased when PLA and PBS are confined in the multinanolayer does not prevent the plasticization phenomenon to occur as revealed by the plasticization coefficient $\gamma \mathrm{C}_{\mathrm{M}}$ which, however, is slightly reduced compared to those of PLA and PBS (Table 3). It is known that the water plasticization phenomenon exists in dense material without highly increasing the solubility while increasing highly the diffusivity such as for glassy and semi-crystalline polymer, MXD6 for example [58-60]. In this latter case, the water diffusivity is increased to such a point that rearrangement of amorphous chains induces crystallization while the water solubility remains low. In literature the plasticization phenomenon is usually able to influence diffusivity but not so much solubility, except in the case of a very high plasticization effect which can induce relaxation and then increase highly the sorption capacity (such as organic vapor in polyamide PA6). For PLA/PBS the plasticization effect is not so important, so the solubility would be more influenced by the confinement effect than by the swelling effect.

The comparison of the values of the coefficients $D_{0}$ and $D_{M}$ allows us to confirm that the structure of the film in multilayer form has not modified the water diffusion mechanism (no increase of tortuosity) and 

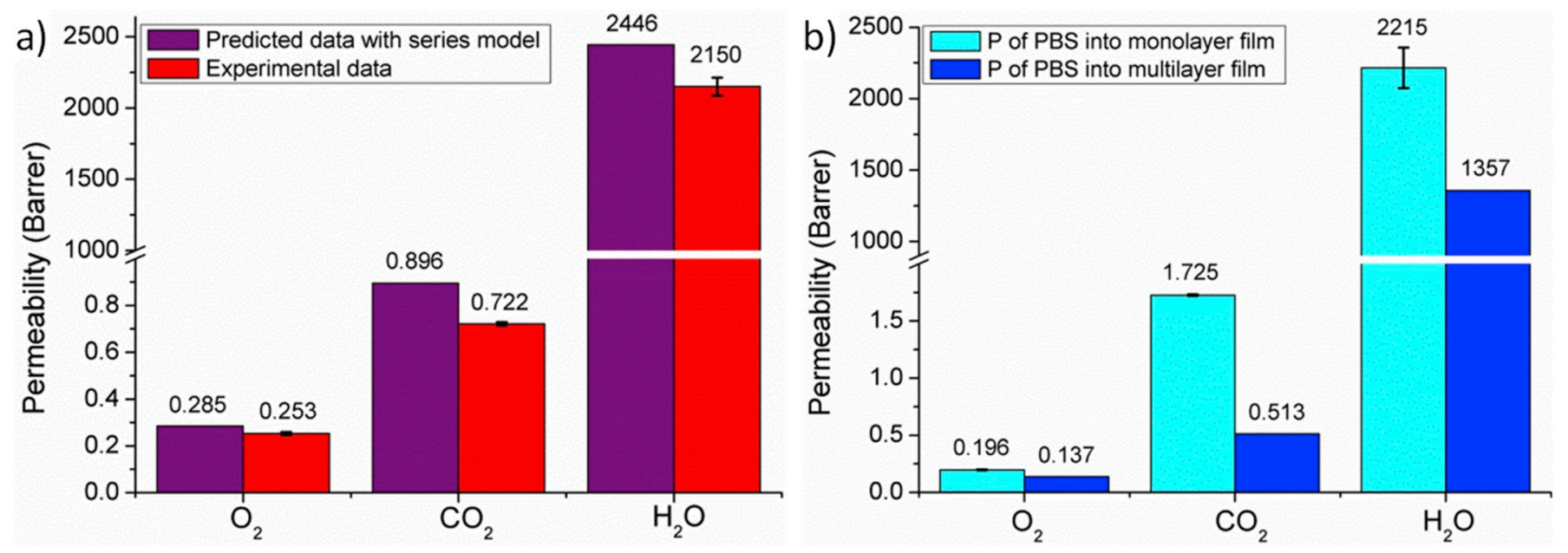

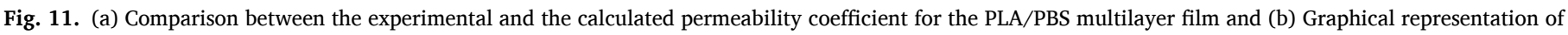
the improvement of PBS barrier properties.

that the improvement of the barrier properties would result rather from a decrease in the solubility coefficient. This hypothesis is also consistent with the fact that the value of the water concentration in the multilayer film, measured at the stationary state, $\mathrm{C}_{\mathrm{M}}$, is lower than that of the two monolayer films. The reduction of water concentration $\mathrm{C}_{M}$ (Table 3 ) in the PLA/PBS assembly compared to PLA and PBS films clearly indicates a reduction of water sorption capacity of the PLA/PBS multilayer due to the denser structure induced by the confinement. In other words, despite the plasticization effect which can create fluctuating free volumes, the permanent free spaces reduced by the confinement effect is much more important. It is remarkable to see that the water barrier effect due to the reduction of solubility is consistent with gas permeation results for which the barrier effect was also explained by the solubility decrease. Moreover, our results are quite different from most of the results obtained with multinanolayer films since they demonstrate that the confinement impacts the transport properties through the decrease of solubility.

As previously mentioned, the multilayer PLA/PBS film could have more barrier properties than those of these two polymers separately, especially to carbon dioxide. However, in the case of nitrogen, the experimental value is greater than the value obtained with the series model, meaning that the multilayer structure did not lead to an improvement of the barrier effect for this gaz. To determine the gain of barrier improvement but also to estimate the magnitude of the confinement effect, we compared the values of the experimental permeability coefficients obtained for the PLA/PBS multilayer film to the predicted values by applying the series model equation (Eq. (7)). This comparison of the permeability coefficients is presented Fig. 11 a. The experimental values of gases and water permeabilities, lower than the theoretical values, clearly highlight the confinement effect in the PLA/PBS multilayer film.

Considering that PLA, the major polymer (80\%), is in an amorphous state, it is supposed not to be affected by the multilayer structure. It is besides assumed that the decrease in the glass transition temperature of the PLA, obtained from the DMTA analysis, was not enough to influence the structure and the molecular mobility of the PLA chains. It is therefore possible to calculate the permeability of the PBS when it was under multilayer form using Equation (9).

$P_{P B S} \quad \frac{\varnothing_{P B S}}{\frac{1}{P_{\text {flim }}}} \frac{\varnothing_{P L A}}{P_{P L A}}$

This calculated value was then compared to the value of the PBS monolayer film (Fig. 11 b). It is remarkable that a high barrier improvement to carbon dioxide was obtained. In a quantitative approach, a Barrier Improvement Factor, named BIF, was determined and divided by the permeability of the PBS in the monolayer form. Thus, the confinement effect induced in the multinanolayer structure PLA/PBS via the force assembly coextrusion allows to improve significantly the barrier performance of the PBS layers, with a BIF reaching $30 \%$ for oxygen, $39 \%$ for water and $70 \%$ for carbon dioxide. This difference can be explained by the fact that for dioxygen and water molecules, only the solubility is impacted by the multilayer structure while the carbon dioxide has an impact on the solubility and also on the diffusivity, probably due to its higher steric hindrance. The case of water is more complex in terms of diffusivity due to its ability to plasticize both PLA and PBS.

\section{Conclusion}

In this work, we successfully developed a new translucent biodegradable film with two polyesters, one amorphous (PLA) and the second semi-crystalline (PBS). The designed multilayer PLA/PBS film presents no delamination while these two polymers are immiscible, and improved gas and water barrier properties, compared to neat PLA and PBS. The forced assembly of $80 \%$ PLA and $20 \%$ PBS into a film made of alternating nanolayers led to an improvement of the PBS barrier properties of $30 \%$ to oxygen, $39 \%$ to water and $70 \%$ to carbon dioxide. To explain this, a reduction in solubility probably due to a decrease in free volume induced by the confinement of PBS layers, has been demonstrated. Such a biodegradable film with improved barrier properties appears as a promising and competitive material for packaging, presenting good mechanical and thermal properties while maintaining a certain transparency.

\section{Declaration of competing interest}

The authors declare no conflict of interest.

\section{Acknowledgment}

The authors thank the GRR Crunch (supported by Upper Normandy region, France) for the financial support of the $\mathrm{PhD}$ fellowship of $\mathrm{T}$. Messin. 


\section{Author contribution statement}

Tiphaine Messin: PhD student, Elaboration of multilayer, Characterization, calculation, analysis, writing the initial draft of the paper, revision of the paper.

Stephane Marais: Supervisor, Acquisition of the financial support, Permeation calculation, simulation (software code), analysis, revision of the paper.

Nadege Follain: Co-supervisor, Acquisition of the financial support, Permeation analysis, revision of the paper.

Alain Guinault: Elaboration of multilayers, DMA measurements, revision of the paper.

Valerie Gaucher: XRD measurements, analysis, revision of the paper. Nicolas Delpouve: DSC measurements, analysis, revision of the paper.

Cyrille Sollogoub: Elaboration of multilayers, DMA measurements, AFM, analysis, revision of the paper.

\section{References}

[1] V. Siracusa, P. Rocculi, S. Romani, M. Dalla Rosa, Biodegradable polymers for food packaging: a review, Trends Food Sci. Technol. 19 (2008) 634-643.

[2] J. Ahmed, S.K. Varshney, Polylactides-Chemistry, properties and green packaging technology: a review, Int. J. Food Prop. 14 (2011) 37-58.

[3] N. Peelman, P. Ragaert, B. De Meulenaer, D. Adons, R. Peeters, L. Cardon, F. Van Impe, F. Devlieghere, Application of bioplastics for food packaging, Trends Food Sci. Technol. 32 (2013) 128-141.

[4] G. Kfoury, J.-M. Raquez, F. Hassouna, J. Odent, V. Toniazzo, D. Ruch, P. Dubois, Recent edvances in high performance poly(lactide) from "green" plasticization to super-tough materials via (reactive) compounding, Front. Chem. 1 (32) (2013) $1-46$.

[5] M. Wang, Y. Wu, Y.-D. Li, J.-B. Zeng, Progress in toughening poly(lactic acid) with renewable polymers, Polym. Rev. 57 (2017) 557-593.

[6] N. Tenn, N. Follain, K. Fatyeyeva, J.M. Valleton, F. Poncin-Epaillard, N. Delpouve, S. Marais, Improvement of water barrier properties of poly(ethylene-co-vinyle alcohol) films by hydrophobic plasma surface treatments, J. Phys. Chem. Part C. 116 (2012) 12599-12612.

[7] N. Tenn, N. Follain, K. Fatyeyeva, F. Poncin-Epaillard, C. Labrugere, S. Marais, Impact of hydrophobic plasma treatments on the barrier proeprties of poly(lactic acid) film, RCS Adv 4 (2014) 5626-5637.

[8] T. Dong, S.X. Song, M. Liang, Y. Wang, X.J. Qi, Y.Q. Zhang, X.Y. Yun, Y. Jin, Gas permeability and permselectivity of poly(L-lactic acid)/SiOx film and its application in equilibrium-modified atmosphere packaging for chilled meat, J. Food Sci. 82 (2017) 97-107.

[9] S. Mattioli, M. Peltzer, E. Fortunati, I. Armentano, A. Jimenez, J.M. Kenny, Structure, gas-barrier properties and overall migration of poly(lactic acid) films coated with hydrogenated amorphous carbon layers, Carbon 63 (2013) 274-282.

[10] N. Tenn, N. Follain, J. Soulestin, R. Cretois, S. Bourbigot, S. Marais, Effect of nanoclay hydration on barrier properties of PLA/montmorillonite base nanocomposites, J. Phys. Chem. C 117 (2013) 12117-12135.

[11] S. Charlon, N. Follain, C. Chappey, E. Dargent, J. Soulestin, M. Sclavons, S. Marais, Improvement of barrier properties of bio-based polyester nanocomposite membranes by water-assisted extrusion, J. Membr. Sci. 496 (2015) 185-198.

[12] E. Picard, E. Espuche, R. Fulchiron, Effect of an organo-modified montmorillonite on PLA crystallization and gas barrier properties, Appl. Clay Sci. 53 (2011) 58-65.

[13] R.M. Rasal, A.V. Janorkar, D.E. Hirt, Poly(lactic acid) modifications, Prog. Polym. Sci. 35 (2010) 338-356.

[14] W.J. Schrenk, Google Patents, 1973.

[15] W.J. Schrenk, N.L. Bradley, T. Alfrey Jr., H. Maack, Interfacial flow instability in multilayer coextrusion, Polym. Eng. Sci. 18 (1978) 620-623.

[16] H. Wang, J.K. Keum, A. Hiltner, E. Baer, B. Freeman, A. Rozanski, A. Galeski, Confined crystallization of polyethylene oxide in nanolayer assemblies, Science 323 (2009) 757-760.

[17] Y. Lin, A. Hiltner, E. Baer, A new method for achieving nanoscale reinforcement of biaxially oriented polypropylene film, Polymer 51 (2010) 4218-4224.

[18] M. Boufarguine, A. Guinault, G. Miquelard-Garnier, C. Sollogoub, PLA/PHBV films with improved mechanical and gas barrier properties, Macromol. Mater. Eng. 298 (2013) 1065-1073.

[19] G. Zhang, P.C. Lee, S. Jenkins, J. Dooley, E. Baer, The effect of confined spherulite morphology of high-density polyethylene and polypropylene on their gas barrier properties in multilayered film systems, Polymer 55 (2014) 4521-4530.

[20] T. Ebeling, A. Hiltner, E. Baer, Delamination failure mechanisms in microlayers of polycarbonate and poly(styrene-co-acrylonitrile), J. Appl. Polym. Sci. 68 (1998) 793-805.

[21] J. Kerns, A. Hsieh, A. Hiltner, E. Baer, Mechanical behavior of polymer microlayers, Macromol. Symp. 174 (1999) 15-25.

[22] C.Y. Lai, A. Hiltner, E. Baer, L.T.J. Korley, Deforamtion of confined poly(ethylene oxide) in multilayer films, ACS Appl. Mater. Interfaces 4 (2012) 2218-2227.
[23] A.M. Jordan, W.R. Lenart, J.M. Carr, E. Baer, T.J. Korley, Structural evolution during mechanical deformation in high-barrier PVDF-TFE/PET multilayer films using in situ x-ray techniques, ACS Appl. Mater. Interfaces 6 (2014) 3987-3994.

[24] T. Kazmierczak, H. Song, A. Hiltner, E. Baer, Polymeric one-dimensional photonic crystals by continuous coextrusion, Macromol. Rapid Commun. 28 (2007) 2210-2216.

[25] C. Ryan, C.W. Christenson, B. Valle, A. Saini, J. Lott, J. Johnson, D. Schiraldi, C. Weder, E. Baer, K.D. Singer, J. Shan, Roll-to-roll fabrication of multilayer films for high capacity optical data storage, Adv. Mater. 24 (2012) 5222-5226.

[26] H.P. Wang, J.K. Keum, A. Hiltner, E. Baer, Crystallization kinetics of poly(ethylene oxide) in confined nanolayers, Macromolecules 43 (2010) 3359-3364.

[27] M. Ponting, Y. Lin, J.K. Keum, A. Hiltner, E. Baer, Effect of substrate on the isothermal crystallization kinetics of confined poly( $\varepsilon$-caprolactone) nanolayers, Macromolecules 43 (2010) 8619-8627.

[28] T. Messin, N. Follain, A. Guinault, C. Sollogoub, V. Gaucher, N. Delpouve, S. Marais, Structure and barrier properties of multinanolayered biodegradable PLA/PBSA: confinement effect via forced assembly coextrusion, ACS Appl. Mater. Interfaces 9 (2017) 29101-29112.

[29] Y. Deng, N.L. Thomas, Blending poly(butylene succinate) with poly(lactic acid): ductility and phase inversion effects, Eur. Polym. J. 71 (2015) 534-546.

[30] T. Yokohara, M. Yamagichi, Structure and properties for biomass-based polyester blends of PLA and PBS, Eur. Polym. J. 44 (2008) 677-685.

[31] D. Wu, L. Yuan, E. Laredo, M. Zhang, W. Zhou, Interfacial properties, viscoelasticity, and thermal behaviors of poly(butylene succinate)/polylactide blend, Ind. Eng. Chem. Res. 51 (2012) 2290-2298.

[32] L. Xie, H. Xu, B. Niu, X. Ji, J. Chen, Z.-M. Li, B.S. Hsiao, G.-J. Zhong, Unprecedented access to strong and ductile poly(lactic acid) by introducing in situ nanofibrillar poly(butylene succinate) for green packaging, Biomacromolecules 15 (2014) 4054-4064.

[33] L. Xie, H. Xu, J.-B. Chen, Z.-J. Zhang, B.S. Hsiao, G.-J. Zhong, J. Chen, Z.-M. Li, From nanofibrillar to nanolaminar poly(butylene succinate): paving the way to robust barrier and mechanical properties for full-biodegradable poly(lactic acid) films, ACS Appl. Mater. Interfaces 7 (2015) 8023-8032.

[34] Y.J. Phua, N.S. Lau, K. Sudesh, W.S. Chow, Z.A. Mohd Ishak, Biodegradability studies of poly(butylene succinate)/organo-montmorillonite nanocomposites under controlled compost soil conditions: effects of clay loading and compatibiliser, Polym. Degrad. Stab. 97 (2012) 1345-1354.

[35] X. Monnier, S. Fernandes Nassar, S. Domenek, A. Guinault, C. Sollogoub, E. Dargent, N. Delpouve, Reduced physical aging rates of polylactide in polystyrene/polylactide multilayer films from fast scanning calorimetry, Polyme 158 (2018) 1-9.

[36] T. Messin, N. Follain, A. Guinault, G. Miquelard-Garnier, C. Sollogoub, N. Delpouve, V. Gaucher, S. Marais, Confinement effect in PC/MXD6 multilayer films: impact of the microlayered structure on water and gas barrier properties, J. Membr. Sci. 525 (2017) 135-145.

[37] M. Gupta, Y. Lin, T. Deans, E. Baer, A. Hiltner, D.A. Schiraldi, Structure and gas barrier properties of poly(propylene-graft-maleic anhydride)/phosphate glass composites prepared by microlayer coextrusion, Macromolecules 43 (2010) $4230-4239$.

[38] V. Prattipati, Y.S. Hu, S. Bandi, D.A. Schiraldi, A. Hiltner, E. Baer, S. Mehta, Effect of compatibilization on the oxygen-barrier properties of poly(ethylene terephthalate)/poly(m-xylylene adipamide) blends, J. Appl. Polym. Sci. 97 (2005) 1361-1370.

[39] H. Wang, J.K. Keum, A. Hiltner, E. Baer, Confined crystallization of PEO in nanolayered films impacting structure and oxygen permeability, Macromolecules 42 (2009) 7055-7066.

[40] A. Bironeau, J. Dirrenberger, C. Sollogoub, G. Miquelar-Garnier, S. Roland, Evaluation of morphological representative sample sizes for nanolayered polymer blends, J. Microsc. 264 (2016) 48-58.

[41] M.S. Nikolic, J. Djonlagic, Synthesis and characterization of biodegradable poly (butylene succinate-co-butylene adipates)s, Polym. Degrad. Stab. 74 (2001) 263-270.

[42] Y.J. Phua, W.S. Chow, A. Mohd Ishak, Mechanical properties and structure development in poly(butylene succinate)/organo-montmorillonite nanocomposites under uniaxial cold rolling, Express Polym. Lett. 5 (2011) 93-103.

[43] Z. Duan, N.L. Thomas, W. Huang, Water vapour permeability of poly(lactic acid) nanocomposites, J. Membr. Sci. 445 (2013) 112-118.

[44] M. Reading, D. Price, H. Orliac, Measurement of crystallinity in polymers using modulated temperature differential scanning calorimetry, in: A. Riga, L. Judovits (Eds.), Materials Characterization by Dynamic and Modulated Thermal Analytical Techniques, ASTM International, West Conshohocken, PA, 2001, pp. 17-31.

[45] A. Esposito, N. Delpouve, V. Causin, A. Dhotel, L. Delbreilh, E. Dargent, From a three-phase model to a continuous description of molecular mobility in semicrystalline poly(hydroxybutyrate-co-hydroxyvalerate), Macromolecules 49 (2016) 4850-4861.

[46] A. Bironeau, T. Salez, G. Miquelard-Garnier, C. Sollogoub, Existence of a critical layer thickness in PS/PMMA nanolayered films, Macromolecules 50 (10) (2017) 4064-4073.

[47] J. Feng, Z. Zhang, A. Bironeau, A. Guinault, G. Miquelard-Garnier, C. Sollogoub, A. Olah, E. Baer, Breakup behavior of nanolayers in polymeric multilayer systems creation of nanosheet and nanodroplets, Polymer 143 (2018) 19-27.

[48] L. Bao, J.R. Dorgan, D. Knauss, S. Hait, N.S. Oliveira, I.M. Maruccho, Gas permeation properties of poly(lactic acid) revisited, J. Membr. Sci. 285 (2006) $166-172$. 
[49] T. Komatsuka, A. Kusakabe, K. Nagai, Characterization and gas transport properties of poly(lactic acid) blend membranes, Desalination 234 (2008) 212-220.

[50] R.T. Chern, W.J. Koros, H.B. Hopfenberg, V.T. Stannett, Material selection for membrane-based gas separations, in: Materials Science of Synthetic Membranes, American Chemical Society, 1985, pp. 25-46.

[51] R. Cretois, N. Follain, E. Dargent, J. Soulestin, S. Bourbigot, S. Marais, L. Lebrun, Microstructure and barrier properties of PHBV/organoclays bionanocomposites, J. Membr. Sci. 467 (2014) 56-66.

[52] S. Prager, F.A. Long, Diffusion of hydrocarbons in polyisobutylene, J. Am. Chem. Soc. 73 (1951) 4072-4075.

[53] J. Crank, G.S. Park, Diffusion in Polymers, Academic Press, London and New York, 1968.

[54] S. Marais, Q.T. Nguyen, C. Devallencourt, M. Metayer, T.U. Nguyen, P. Schaetzel, Permeation of water through polar and nonpolar polymers and copolymers: determination of the concentration-dependent diffusion coefficient, J. Polym. Sci. Part B 38 (2000) 1998-2008.

[55] N. Follain, J.-M. Valleton, L. Lebrun, B. Alexandre, P. Schaetzel, M. Metayer, S. Marais, Simulation of kinetic curves in mass transfer phenomena for concentration-dependent diffusion coefficient in polymer membranes, J. Membr. Sci. 349 (2010) 195-207.

[56] S. Charlon, S. Marais, E. Dargent, J. Soulestin, M. Sclavons, N. Follain, Structure-barrier property relationship of biodegradable poly(butylene succinate) and poly[(butylene succinate)-co-(butylene adipate)] nanocomposites: influence of the rigid amorphous fraction, Phys. Chem. Chem. Phys. 17 (2015) 29918-29934.

[57] S. Charlon, N. Follain, J. Soulestin, M. Sclavons, S. Marais, Water transport properties of poly(butylene succinate) and poly[(butylene succinate)-co-(butylene adipate)] nanocomposite films: influence of the water-assisted extrusion process, J. Phys. Chem. Part C. 121 (2017) 918-930.

[58] B. Ben Doudou, E. Dargent, S. Marais, J. Grenet, Y. Hirata, Barrier properties and microstructure modifications induced by liquid water for a semiaromatic polyamide, J. Polym. Sci. Part B. 43 (2005) 2604-2616.

[59] T. Messin, S. Marais, N. Follain, C. Chappey, A. Guinault, G. Miquelard-Garnier, N. Delpouve, V. Gaucher, C. Sollogoub, Impact of water and thermal induced crystallizations in a PC/MXD6 multilayer film on barrier properties, Eur. Polym. J. 111 (2019) 152-160.

[60] C. Lixon Buquet, B. Ben Doudou, C. Chappey, E. Dargent, S. Marais, Permeation properties of poly(m-xylene adipamide) membranes, J. Phys. Chem. Part B 113 (2009) 3445-3452. 